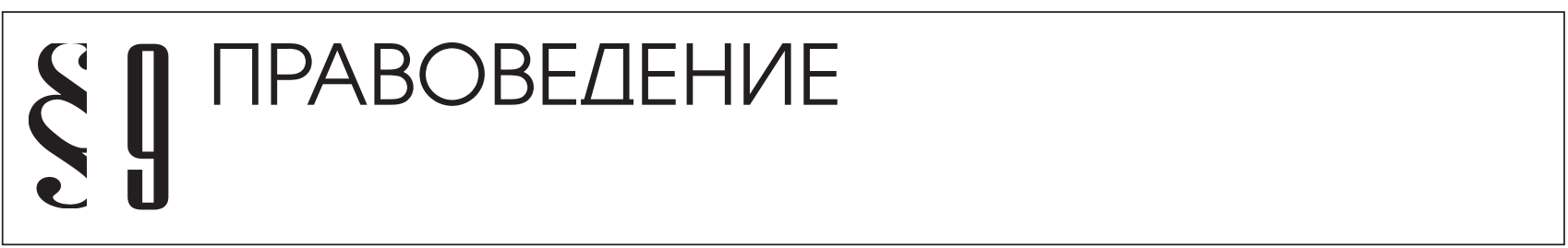

Беляев В.П.

\title{
КОНТРОЛЬНАЯ И НАДЗОРНАЯ ЮРИДИЧЕСКАЯ ДЕЯТЕЛЬНОСТЬ: К ВОПРОСУ О РАЗГРАНИЧЕНИИ ПОНЯТИЙ
}

\author{
Публикация подготовлена в рамках выполнения государственного \\ задания Министерства образования и науки Российской Федерации \\ по теме: «Юридическая деятельность и ее процессуальное оформление» (заявка 2014/ 78)
}

\begin{abstract}
Аннотация: В решающей степени целью настоящей работы является стремление автора к уяснению реального соотношения контрольной и надзорной юридической деятельности, в том числе и путем анализа их различий на основе высказанных в науке точек зрения по названной проблеме. Как известно, в современной России осуществляются коренные преобразования, в значительной степени затрагивающие функиионирование государственного механизма, важными элементами которого выступают контрольная и надзорная деятельность. Перед органами контроля и надзора ставятся новые задачи по укреплению законности, правопорядка и дисциплины, от них требуется повышение их эффективности, оптимизация деятельности. Все изложенное в значительной меры обусловливается комплексным и углубленным научным освоением проблемы соотношения контрольной и надзорной юридической деятельности именно с общетеоретических позиций. При подготовке статьи использованы различные общенаучные приемы и способы логического познания: анализ и синтез, абстрагирование, моделирование, системно-структурный, функииональный и формально-логический подходы. Специальнье методыл представлены конкретно-сочиологическим и статистическим, а частнонаучные - формально-юридическим, сравнительно-правовым и методом толкования норм права. Комплексный теоретико-прикладной междисциплинарный подход к исследованию проблемы обусловил необходимость использования системного метода, в рамках которого осуществлено интегрирование теоретических абстракций и положений, закрепленных в действующем законодательстве. Используемая методология при исследовании контрольной и надзорной юридической деятельности в общетеоретической плане позволяет: во-первых, преодолеть отставание в научном освоении названных видов деятельности от отраслевых наук; во-вторых, показать фактическое (и реальное, существующее в природе) различие сущности контроля и надзора, выявить критерии (основания) такого различия; в-третьих, предложить определеннье рекомендации (направления) в цеелях оптимизации контрольной и надзорной деятельности, внедрения их в законотворческую и правоприменительную практику.
\end{abstract}

Abstract: To a great extent, the purpose of this work is the desire of the author to elucidate the real correlation of control and supervisory legal work, including by analyzing the differences between them on the basis of views expressed on the said issue. As we know, the modern Russia is undergoing fundamental transformations that largely affect the functioning of the state mechanism, important elements of which are the control and supervision activities. Control and supervision bodies face new challenges on strengthening law, order and discipline; they need to increase their efficiency and optimize the activities. All the foregoing is largely determined by a complex and in-depth scientific development of the relation of control and supervisory legal activities, precisely from the general theoretical positions. When preparing the article, the author used different scientific techniques and methods of logical knowledge, such as analysis and synthesis, abstraction, modeling, systematic and structural, functional and formal-logical approaches. Special techniques are presented with concrete sociological and statistical methods, whereas scientific are presented with formal legal and comparative legal methods of law interpretation. Comprehensive theoretical and applied interdisciplinary approach to the problem necessitated the use of a system method, which accomplished the integration of theoretical abstractions and provisions 
DOI: $10.7256 / 1811-9018.2014 .2 .10879$

При цитировании этой статьи сноска на dоі обязательна

\section{Право и политика $2(170) \cdot 2014$}

in the current legislation. In terms of general theory, the methodology used in the study of control and supervisory legal activities gives the possibility, firstly, to overcome the lag in the scientific development of the aforementioned types of activities of industry sciences; secondly, to show the actual (real, existing) difference between the essence of control and supervision, and to identify the criteria (reasons) for this difference; thirdly, to offer certain recommendations (directions) in order to optimize control and supervisory activities by implementing them in legislative and law enforcement practices. Ключевые слова: надзорная юридическая деятельность, контрольная юридическая деятельность, законность, правопорядок, проверка исполнения законов, административные полномочия, различия контроля надзора, государственное управление, оптимизация правового регулирования, государственный механизм.

Keywords: supervisory legal activities, control legal activities, legality, law and order, control of the execution of laws, administrative authority, supervisory control differences, governance, optimization of legal regulation, the state mechanism.

овременному периоду развития России присущи коренные преобразования общественных отношений в соответствии с целями, задачами и принципами построения демократического, социального и правового государства. В процессе обновления общества возникают новые правовые институты, создаются принципиально новые органы государственного механизма, деятельность которого, безусловно, должна отвечать требованиям законности.

Как известно, Конституция РФ закрепила курс на обеспечение верховенства закона, охрану прав и законных интересов граждан, общества и государства. Значимым содержанием наполнены проводимые в стране государственно-правовая, судебная и административная реформа.

В совокупности, все изложенное с необходимостью предполагает эффективное функционирование органов контроля и надзора во всех без исключения сферах общественной жизни государства, требует их оптимизации. Выступая в качестве действенных юридических средств устранения различного рода отступлений от закона и правонарушений, одновременно являясь важнейшими функциями государства, способами и гарантиями обеспечения законности и правопорядка, контрольная и надзорная юридическая деятельность ${ }^{1}$ придают необходимый динамизм происходящим в стране разносторонним преобразованиям, становятся одним из решающих факторов углубления реального демократизма, построения правового государства и гражданского общества.

Безусловно, необходимость дальнейшего исследования теоретических основ контроля и надзора усиливается в связи с радикальной перестройкой системы органов исполнительной власти, в частности,

\footnotetext{
${ }^{1} \mathrm{O}$ контрольной и надзорной юридической деятельности подробнее см., напр.: Беляев В.П. Контроль и надзор в Российском государстве: монография. М., 2005; Назаров С.Н. Надзор в системе видов юридической деятельности // Северо-Кавказский юридический вестник. 2010. № 1. С. 91-98 и другие.
}

функционированием целого ряда федеральных служб, наделенных контрольно-надзорными полномочиями, а также необходимостью научного освоения всего комплекса проблем в деятельности органов надзора, особенно прокуратуры, как главного органа государственного надзора.

Важно подчеркнуть и такое обстоятельство: дальнейшее общетеоретическое исследование контрольной и надзорной юридической деятельности вызывается и рядом других причин: социальными - изменением условий функционирования органов контроля и надзора; теоретическими - потребностью комплексного теоретического осмысления сущности и содержания контроля и надзора, а также уяснения сходства и различий этих видов юридической деятельности, что позволит более четко установить их функциональную принадлежность; практическими - оптимизацией контрольной и надзорной деятельностиㄴ. Этим в основном и объясняется замысел настоящей работы.

Прежде всего, надо сказать, что анализ научной литературы по рассматриваемой проблематике позволяет сделать вывод, что на протяжении многих лет внимание исследователей было сосредоточено на изучении вопросов организации и деятельности контрольных и надзорных органов путем рассмотрения их нормативно-правовой регламентации, полномочий, функций, методов и т.п.

Однако выполненные представителями различных отраслей права работы не снижают актуальности дальнейшего научного освоения контрольной и надзорной юридической деятельности. Тем более, что общетеоретических исследований контроля и надзора в качестве автономных форм юридической деятельности на современном этапе явно недостаточно. В этой связи полностью оправданным является замечание

\footnotetext{
${ }^{2}$ Сегодня в стране более миллиона проверяющих; в России пройдет «инвентаризация полномочий контрольно-надзорных ведомств // Зыкова Т. Контролеров тоже проверят // Российская газета. 2013. 20 декабря (№ 288).
} 
С.Ф. Довлетова о том, что несмотря на достаточное количество работ, посвященных проблемам контроля и надзора, необходимо признать, что теория государства и права уступает отраслевым юридическим наукам в исследовании данной проблематики ${ }^{3}$.

В продолжение, со своей стороны отметим, что имеющиеся научные публикации далеко не всегда затрагивают такой практически важный вопрос, как разграничение самих понятий контроля и надзора, далеко не всегда говорится о различении сущности и содержания контрольной и надзорной деятельности.

В этом плане вначале следует сказать о том, что действующее законодательство практически не разграничивает понятия контроля и надзора, в текстах законов и других нормативно-правовых актах они используются как равнозначные.

Так, если обратиться к законодательству о системе органов исполнительной власти, то видно, что в соответствии с ним на все федеральные службы возложены функции по надзору и контролю ${ }^{4}$. Однако, к примеру, даже в названии Федеральной службы по техническому и экспортному контролю нет упоминания о надзоре, тогда как название службы финансово-бюджетного надзора не содержит термина «контроль».

Следовательно, даже при определении наименования (названия) той или иной контролирующей (надзорной) структуры по-прежнему разграничение понятий «контроль» и «надзор» не проводится. Анализ функционального предназначения федеральных служб также не дает ответа на вопрос, где - контроль, а где - надзор. Но это обстоятельство оставим, как говорится, на совести законодателя, то есть тех, кто принимает законы.

Совсем другое дело, когда ученые и практикующие юристы также поступают аналогичным образом, далеко не всегда упоминают (тем более утверждают) о различиях между контролем и надзором, а также органами, их осуществляющими; во многих работах, представляющих разные отрасли правоведения, термины «контроль» и «надзор» употребляются как синонимы, нередко - произвольно, без объяснения смыслового наполнения.

При анализе сложившейся ситуации, полагаем, уместно сослаться на высказывание А.В. Ерицяна, когда он пишет, что мнения ученых юристов по по-

\footnotetext{
${ }^{3}$ Довлетов С.Ф. Категории «контроль « и «надзор»: сущность понятия и их соотношение // Вестник Владимирского юридического института. 2008. № 4 (9). С. 125.

${ }^{4}$ Указ Президента РФ от 09.03.2004 № 314 (ред. от 22.06.2010) «О системе и структуре федеральных органов исполнительной власти» // СЗ РФ. 2004. № 11. Ст. 945.
}

воду содержания данных правовых терминов можно разделить на две следующие группы: а) термины «контроль» и «надзор» тождественны (А.П. Алехин, А.А. Кармолицкий); б) надзор, осуществляемый органами государственного управления, является разновидностью контроля (Ю.М. Козлов, В.И. Туровцев, Н.Г. Салищева) $)^{5}$

В свою очередь, по мысли Е.В. Шориной, в системе органов контроля особое место занимает прокуратура ${ }^{6}$. Тогда, исходя из такого посыла, можно предположить, что исключительно надзорный орган прокуратура орган контроля?

Названный автор в своих суждениях не одинок. Фактически так же считают Г.В. Барабашов и С.А. Авакьян, включая прокурорский надзор в общий контроль? А.Е. Лунев, когда говорит о способах обеспечения законности в сфере государственного управления, называет контрольно-надзорную деятельность ${ }^{8}$.

Я.А. Гейвандов полагает, что в широком смысле контроль как социально-правовое явление, проявляется в виде двух самостоятельных направлений: собственно контроль и надзор9. Однако заметим, что при этом ученый делает несколько противоречивый вывод: наблюдение и проверку исполнения принятых решений и правовых норм он называет контрольной деятельностью; с нашей точки зрения, такая деятельность является надзорной.

В подтверждение дискуссионности по названному вопросу можно назвать и другие публикации ${ }^{10}$, тем не менее, их анализ только подчеркнет неоднозначность

\footnotetext{
${ }^{5}$ Ерииян А.В. Государственный контроль за соблюдением законодательства субъектами предпринимательской деятельности (теоретический аспект) // Государство и право. 2002. № 2. С. 103-104.

${ }^{6}$ Шорина Е.В. Контроль за деятельностью органов государственного управления в СССР. М., 1981. С. 110.

${ }^{7}$ Авакьян С.А., Барабашов Г.В. Советы и совершенствование деятельности местных контрольных органов // Вестник МГУ. Серия Право. 1984. № 1. С. 14.

${ }^{8}$ Лунев А.Е. Обеспечение законности в советском государственном управлении. М., 1963. С. 4; Аналогичное мнение высказывает и М.Л. Баранов в своей статье «Конституционно-правовая природа и соотношение понятий «государственный контроль» и «государственный надзор» // Образование и право. 2012. № 10 (38). С. 16-29.

9 Гейвандов Я.А. Содержание и основные направления государственной надзорно-контрольной деятельности в банковской сфере // Юрист. 2000. № 6. С. 24.

${ }^{10}$ См. напр.: Рохлин В.И. О конституционном статусе российской прокуратуры. СПб, 1999; Тарасов А.М. Проблемы законодательного обеспечения государственного контроля // Государство и право. 2004. № 10. С. 17-21; Андреева Ю.А. Контроль и надзор: основные подходы к разграничению понятий // Научный вестник Омской Академии МВД России. 2009. № 1 (32). С. 55-60 и другие.
} 
DOI: $10.7256 / 1811-9018.2014 .2 .10879$

При цитировании этой статьи сноска на dоі обязательна

\section{Право и политика $2(170) \cdot 2014$}

интерпретаций контроля и надзора и нерешенность обозначенной проблемы. Поэтому, безусловно, прав В.Д. Кошлевский, когда пишет, что юриспруденцией стоит задача исследования контрольно-надзорной деятельности государства на теоретико-эмпирическом уровне с целью определения логически правильной конструкции контроля и надзора ${ }^{11}$.

Поскольку тема настоящей работы предопределяет рассмотрение соотношения контроля и надзора, перейдем к обоснованию собственного мнения по этому непростому вопросу.

Прежде всего, следует почеркнуть то важное обстоятельство, что реализация контролирующими органами своих функций преследует не только достижение законности, правопорядка и дисциплины (в широком смысле), но и обеспечение эффективного и целесообразного государственного управления, поставленных задач, установленных регламентов и т.д. М.С. Студеникина по этому поводу пишет, что контроль в отличие от надзора - более широкое понятие, неограниченное кругом вопросов, связанных с соблюдением обязательных предписаний, законов и других актов; государственный контроль - это функция государственного управления, присущая всем государственным органам, независимо от их основных задач и вида деятельности, которые они осуществляют ${ }^{12}$.

В свою очередь, основной целью надзора (его предназначением) является установление точного и неуклонного исполнения поднадзорными органами законов, которое не сопровождается проверкой и оценкой целесообразности совершенных действий и принятых нормативно-правовых актов (управленческого процесса). Главная функция надзорного органа заключается в проверке деятельности (действий) объекта надзора исключительно с точки зрения законодателя.

Далее, характерной чертой контрольной деятельности является наличие у контролирующих органов определенных полномочий исполнительной власти (контроль общеобязательных правил поведения, выдача различного рода разрешений, лицензий и т.п., регистрация прав, актов, документов и т.д.).

В противовес этому, полагаем, надзорные органы не могут наделяться такими (административными,

\footnotetext{
${ }^{11}$ Кошлевский В.Д. Контрольно-надзорная деятельность государства как средство реализации Конституции РФ // Конституция Российской Федерации и современное законодательство: проблемы реализации и тенденции развития. Материалы междунар. науч.практ. конф. Ч. 1. Саратов, 2003. С. 71.

${ }^{12}$ Студеникина М.С. Государственный контроль в сфере управления. Проблемы надведомственного контроля. М., 1974. С. 9.
}

управленческими и т.п.) полномочиями; в противном случае они фактически превратились бы в управленческие структуры, подконтрольные органам исполнительной власти, а это идет вразрез с самой надзорной сущностью (надзорный орган должен быть реально независим - В.Б.).

Продолжая, надо особо обратить внимание на то, что органы контроля вправе сами (непосредственно) применять различные, в том числе и административные, санкции в отношении нарушителей. Они, в отличие от надзорных структур, обладают реальной административной властью: могут издавать акты, обязательные для исполнения подконтрольными органами и должностными лицами, привлекать к административной ответственности. Наряду с этим, органы контроля могут непосредственно сами проводить ревизии хозяйственно-финансовой деятельности, производственно-технические экспертизы, приостанавливать незаконные распоряжения и действия должностных лиц (вплоть до приостановления хозяйственной деятельности предприятий и организаций), то есть фактически вмешиваться в оперативно-хозяйственную деятельность. Примечательно, что последнее обстоятельство прямо запрещается законом, в частности, для органов прокуратуры ${ }^{13}$ (с нашей точки зрения, прокуратура единственный орган надзор за законностью).

Кроме того, отличие контроля от надзора, в частности прокурорского, заключается и в том, что прокуратура является самостоятельным органом государственного надзора, не входящим ни в какую из ветвей государственной власти.

Органы же государственного контроля выполняют свою работу под непосредственным руководством правительства (того или иного министерства, ведомства), фактически все федеральные службы по контролю и надзору входят в систему органов исполнительной власти.

При определении отличий контрольной деятельности от надзорной следует особо подчеркнуть такое важное обстоятельство: только в компетенцию прокуратуры входит проверка исполнения законов самими контролирующими органами (не случайно ранее он назывался «высшим» надзором).

Также отметим, что прокурорский надзор в отличие от контроля охватывает практически все сферы общественных отношений (он «всеяден», «широкозахватен»).

\footnotetext{
${ }^{13}$ Ч. 2 ст. 26 Федерального закона от 17.01. 1999 № 2202-1 (ред. от 25.11.2013) «О прокуратуре Российской Федерации» // СЗ РФ. 1995. № 47. C. 4472.
} 
Напротив, органы, осуществляющие контроль, специализируются в определенных областях общественных отношений, что обусловливается многообразием и сложностью задач управления, множественностью субъектов государственного управления, в отношении которых осуществляется контроль (отсюда проистекают понятия внутриведомственного, надведомственного, межведомственного и т.п. контроля - В.Б.).

Нельзя не сказать и о том, что деятельность такого специального государственного органа надзора, как прокуратура, в отличие от контролирующих органов имеет собственные задачи и цели. Прокурорский надзор в известном смысле является универсальным - объектом его деятельности являются любые сферы правовых отношений. Его главная цель - обеспечение надзора за соблюдением Конституции РФ и исполнением законов, действующих на ее территории, прав и свобод граждан, охраняемых законных интересов общества и государства (в связи с чем мы предлагаем возвратить прокурорскому надзору наименование «высший надзор»).

Об актуальности проблемы соотношения надзора и контроля на современном этапе справедливо пишет М.С. Шалумов: «Приведенная палитра мнений о соотношении прокурорского надзора и государственного контроля достаточно широка. Очевидна необходимость приведения их в систему, определения четких критериев разграничения терминов применительно к сложившемуся в России государственно-правовому механизму. При этом, безусловно, главное, определяющее значение имеют положение, место и роль каждого из сравниваемых институтов в этом механизме» ${ }^{14}$.

Со своей стороны заметим, что мы также последовательно высказываем свою точку зрения, согласно которой, несмотря на внешнее сходство и действительно имеющиеся общие черты, контроль и надзор - это самостоятельные формы юридической деятельности, и их нельзя объединять «под одной крышей», поскольку имеются неоспоримые обстоятельства, свидетельствующие о различии их сущности и содержания (об основных из них мы и вели речь в этой статье).

В заключение отметим, что уяснение принципиальных различий контроля и надзора приобретает особую актуальность в связи с реорганизацией действующей системы контроля как части правового механизма обеспечения законности и совершенствованием правового

${ }^{14}$ Шалумов М.С. Прокурорский надзор и государственный контроль за исполнением законов: разграничение компетенции и ответственности // Государство и право. 1999. № 1. С. 79-85. регулирования надзора в России. Характерные признаки контроля и надзора, определяющие сущность и содержание этих двух форм обеспечения законности и правопорядка, а также их существенное различие, полагаем, должны послужить основой для новых подходов при законодательной регламентации и определении правового статуса органов контроля и надзора. Пришло время уйти от сложившихся стереотипов, устранить имеющиеся противоречия в подходах к различению понимания сущности и содержания контрольной и надзорной деятельности, к их разграничению, что в значительной мере возможно путем разработки и создания соответствующей концепции (теории) соотношения названных видов юридической деятельности, с учетом которой могут быть сформированы как контрольные, так и надзорные структуры с четко определенной компетенцией (и, соответственно, названиями), что позволит конкретно определить их роль и назначение в государственном механизме.

\section{Библиография:}

1. Беляев В.П. Контроль и надзор в Российском государстве: монография. М., 2005.

2. Назаров С.Н. Надзор в системе видов юридической деятельности // Северо-Кавказский юридический вестник. 2010. № 1. С. 91-98.

3. Довлетов С.Ф. Категории «контроль « и «надзор»: сущность понятия и их соотношение // Вестник Владимирского юридического института. 2008. № 4 (9).

4. Ерицян А.В. Государственный контроль за соблюдением законодательства субъектами предпринимательской деятельности (теоретический аспект) // Государство и право. 2002. № 2. С. 103-104.

5. Шорина Е.В. Контроль за деятельностью органов государственного управления в СССР. М., 1981.

6. Авакьян С.А., Барабашов Г.В. Советы и совершенствование деятельности местных контрольных органов // Вестник МГУ. Серия Право. 1984. № 1. С. 14.

7. Лунев А.Е. Обеспечение законности в советском государственном управлении. М., 1963.

8. Баранов М.Л. Конституционно-правовая природа и соотношение понятий «государственный контроль» и «государственный надзор» // Образование и право. 2012. № 10 (38). С. 16-29.

9. Гейвандов Я.А. Содержание и основные направления государственной надзорно-контрольной деятельности в банковской сфере // Юрист. 2000. № 6. 


\section{Право и политика $2(170) \cdot 2014$}

10. Кошлевский В.Д. Контрольно-надзорная деятельность государства как средство реализации Конституции РФ // Конституция Российской Федерации и современное законодательство: проблемы реализации и тенденции развития. Материалы междунар. науч.-практ. конф. Ч. 1. Саратов, 2003. С. 71.

11. Студеникина М.С. Государственный контроль в сфере управления. Проблемы надведомственного контроля. М., 1974. С. 9.

12. Шалумов М.С. Прокурорский надзор и государственный контроль за исполнением законов: разграничение компетенции и ответственности // Государство и право. 1999. № 1. С. 79-85.

13. Овчинников Н.А. К вопросу о понятии законности как одного из направлений противодействия коррупции в системе Министерства внутренних дел России // NB: Российское полицейское право.-2013. - 1. - C. 84-98. URL: http://www.e-notabene.ru/pm/ article_764.html

14. Субанова Н.В. Прокурорский надзор за исполнением законов о разрешительной системе как направление обеспечения национальной безопасности// Национальная безопасность/Nota Bene.-№ 6.-201

15. А. А. Спектор К вопросу о видах и формах проверок при осуществлении государственного контроля (надзора) и муниципального контроля предпринимательской деятельности // Политика и Общество. - 2011. - 12. - С. 58 - 65.

16. Каламкарян Р.А. Роль Международного Суда ООН в деле поддержания международного правопорядка // NB: Международное право. - 2013. - 1. - C. 184 - 214. URL: http://www.e-notabene.ru/wl/ article_690.html

17. Р.А. Каламкарян Роль Международного Суда $\mathrm{OOH}$ в деле поддержания международного правопорядка // Международное право и международные организации / International Law and International Organizations. - 2013. - 1. - C. 92 - 103. DOI: 10.7256/2226-6305.2013.01.6.

18. Каламкарян Р.А. Включенность Российской Федерации в деятельность Международного Суда ООН в деле обеспечения международной законности и правопорядка // NB: Международное право. -2013. -2.-C. 85 - 118. URL: http://www.e-notabene. ru/wl/article_691.html

19. Овчинников Н.А. К вопросу о понятии законности как одного из направлений противодействия коррупции МВД России. // Полицейская деятельность. $-2011 .-1 .-$ С. $5-9$.

\section{References (transliteration):}

1. Belyaev V.P. Kontrol' i nadzor v Rossiiskom gosudarstve: monografiya. M., 2005.

2. Nazarov S.N. Nadzor v sisteme vidov yuridicheskoi deyatel'nosti // Severo-Kavkazskii yuridicheskii vestnik. 2010. № 1. S. 91-98.

3. Dovletov S.F. Kategorii «kontrol' « i «nadzor»: sushchnost' ponyatiya i ikh sootnoshenie // Vestnik Vladimirskogo yuridicheskogo instituta. 2008. № 4 (9).

4. Eritsyan A.V. Gosudarstvennyi kontrol' za soblyudeniem zakonodatel'stva sub"'ektami predprinimatel'skoi deyatel'nosti (teoreticheskii aspekt) // Gosudarstvo i pravo. 2002. № 2. S. 103-104.

5. Shorina E.V. Kontrol' za deyatel'nost'yu organov gosudarstvennogo upravleniya v SSSR. M., 1981.

6. Avak'yan S.A., Barabashov G.V. Sovety i sovershenstvovanie deyatel'nosti mestnykh kontrol'nykh organov // Vestnik MGU. Seriya Pravo. 1984. № 1. S. 14.

7. Lunev A.E. Obespechenie zakonnosti v sovetskom gosudarstvennom upravlenii. M., 1963.

8. Baranov M.L. Konstitutsionno-pravovaya priroda $\mathrm{i}$ sootnoshenie ponyatii «gosudarstvennyi kontrol'» $\mathrm{i}$ «gosudarstvennyi nadzor»// Obrazovanie i pravo. 2012. № 10 (38). S. 16-29.

9. Geivandov Ya.A. Soderzhanie i osnovnye napravleniya gosudarstvennoi nadzorno-kontrol'noi deyatel'nosti v bankovskoi sfere // Yurist. 2000. № 6.

10. Koshlevskii V.D. Kontrol'no-nadzornaya deyatel'nost' gosudarstva kak sredstvo realizatsii Konstitutsii RF // Konstitutsiya Rossiiskoi Federatsii i sovremennoe zakonodatel'stvo: problemy realizatsii i tendentsii razvitiya. Materialy mezhdunar. nauch.-prakt. konf. Ch. 1. Saratov, 2003. S. 71.

11. Studenikina M.S. Gosudarstvennyi kontrol' v sfere upravleniya. Problemy nadvedomstvennogo kontrolya. M., 1974. S. 9.

12. Shalumov M.S. Prokurorskii nadzor i gosudarstvennyi kontrol' za ispolneniem zakonov: razgranichenie kompetentsii i otvetstvennosti // Gosudarstvo i pravo. 1999. № 1. S. 79-85.

13. Ovchinnikov N.A. K voprosu o ponyatii zakonnosti kak odnogo iz napravlenii protivodeistviya korruptsii v sisteme Ministerstva vnutrennikh del Rossii // NB: Rossiiskoe politseiskoe pravo.-2013.-1.-C. 84-98. URL: http://www.e-notabene.ru/pm/article_764.html

14. Subanova N.V. Prokurorskii nadzor za ispolneniem zakonov o razreshitel'noi sisteme kak napravlenie obespecheniya natsional'noi bezopasnosti//Natsional'naya bezopasnost'/Nota Bene.-№ 6.-201 
DOI: $10.7256 / 1811-9018.2014 .2 .10879$

При цитировании этой статьи сноска на dоі обязательна

Правоведение

15. A. A. Spektor K voprosu o vidakh i formakh proverok pri osushchestvlenii gosudarstvennogo kontrolya (nadzora) i munitsipal'nogo kontrolya predprinimatel'skoi deyatel'nosti // Politika i Obshchestvo. - 2011. - 12. - C. $58-65$.

16. Kalamkaryan R.A. Rol' Mezhdunarodnogo Suda OON v dele podderzhaniya mezhdunarodnogo pravoporyadka // NB: Mezhdunarodnoe pravo. - 2013. - 1 . - C. 184 - 214. URL: http://www.e-notabene.ru/wl/ article_690.html

17. R.A. Kalamkaryan Rol' Mezhdunarodnogo Suda OON $\mathrm{v}$ dele podderzhaniya mezhdunarodnogo pravoporyadka // Mezhdunarodnoe pravo i mezhdunarodnye organizatsii / International Law and International Organizations. - 2013. - 1. - C. $92-103$. DOI: 10.7256/2226-6305.2013.01.6.

18. Kalamkaryan R.A. Vklyuchennost' Rossiiskoi Federatsii v deyatel'nost' Mezhdunarodnogo Suda OON v dele obespecheniya mezhdunarodnoi zakonnosti i pravoporyadka // NB: Mezhdunarodnoe pravo. -2013. -2. - C. 85 - 118. URL: http://www.e-notabene. $\mathrm{ru} / \mathrm{wl} /$ article_691.html

19. Ovchinnikov N.A. K voprosu o ponyatii zakonnosti kak odnogo iz napravlenii protivodeistviya korruptsii MVD Rossii. // Politseiskaya deyatel'nost'. - 2011. 1. - C. $5-9$. 